\title{
Use of environmental sensors and sensor networks to develop water and salinity budgets for seasonal wetland real-time water quality management
}

\author{
Nigel W.T. Quinn ${ }^{1,4}$, Ricardo Ortega ${ }^{2,3}$, Patrick J.A. Rahilly ${ }^{3}$ and Caleb W. Royer ${ }^{1,3}$ \\ ${ }^{1}$ Lawrence Berkeley National Laboratory, Berkeley, California; California Department of \\ Fish and Game, Los Banos, California ${ }^{2}$; Grassland Water District, Los Banos, California ${ }^{3}$, US \\ Bureau of Reclamation ${ }^{4}$
}

\section{Abstract}

Successful management of river salt loads in complex and highly regulated river basins such as the San Joaquin of California presents significant challenges to Information Technology. Models are used as means of simulating major hydrologic processes in the basin which affect water quality and can be useful as tools for organizing basin information in a structured and readily accessible manner. Models can also be used to extrapolate the results of system monitoring since it is impossible to collect data for every point and non-point source of a pollutant in the Basin. Fundamental to every model is the concept of mass balance. This paper describes the use of state-of-the-art sensor technologies deployed in concert to obtain the first water and salinity budgets for a 60,000 hectare tract of seasonally managed wetlands in the San Joaquin Basin of California. These sensor technologies are being combined with more traditional sensor techniques to support real-time water quality management (RTWQM) in the River Basin. This paper focuses on two innovative technologies - one, YSI Econet, which deals with continuous flow and salinity monitoring of surface water deliveries and seasonal wetland drainage and the second a remote sensing technology for mapping soil 
salinity in the surface soils of these wetland areas. The paper describes the use of more traditional sensor technologies including a weather station, used to estimate wetland pond evaporation and moist soil plant evapotranspiration and in-situ groundwater water table loggers, used to estimate wetland pond seepage. The paper also discusses the problems associated with continuous data quality assurance and introduces a new software product which streamlines the process of data error correction and dissemination as part of a real-time salinity (RTSM) management program in the San Joaquin Basin.

\section{Introduction}

Real-time water quality management (RTWQM) is a strategy for meeting downstream water quality objectives by improving coordination of upstream contaminant loading from nonpoint sources with dilution flows by making use of river assimilative capacity. Assimilative capacity for a contaminant such as salinity is defined as the maximum loading of that contaminant that can be accommodated by the river without exceeding water quality objectives, typically defined at a downstream compliance monitoring location. In the case of the San Joaquin Basin of California reservoir releases from tributaries on the East-Side of the River Basin (mostly snow-melt from the granitic Sierra Nevada mountains and return flows from east-side irrigation districts) provide dilution to west-side San Joaquin Basin drainage flows, derived mostly from irrigated agricultural crop land and seasonally managed wetlands. The west-side soils derive from eroded sediments from an uplifted marine and are high in naturally occurring salts. Water supplies for irrigation of west-side agriculture and for the seasonally managed wetlands (Figure 1) derive from the Sacramento-San Joaquin River Delta and contain salt - most often in the range of $300-600$ ppm TDS. West-side agricultural return flows are at their highest during the summer irrigation season. Seasonal wetland salt loads are highest during the months of March and April when the majority of the seasonal 
wetland ponds are drawn down to promote establishment of moist soil plants and other native grasses that provide a protein source to overwintering waterfowl. Salt export from agricultural, wetland and municipalities is regulated as part of a comprehensive TMDL for the San Joaquin River Basin (EPA, 2002; Quinn and Karkoski, 1998). Total Maximum Daily Loads (TMDL's) limit agricultural and wetland discharges of salt loads to the SJR. During dry and critically dry years the salt TMDL is especially restrictive curtailing salt load from irrigated agricultural land during the summer months when drainage return flows are typically highest. Under these hydrologic conditions dilution flows from the Sierran tributaries to the San Joaquin River (SJR) diminish and River assimilative capacity is likewise reduced resulting in greater frequency of violation of the State water quality objective for salinity.

Real-time salinity management (RTSM) has been advocated as a means of improving compliance with SJR salinity objectives by improving the coordination of west-side agricultural and wetland dischargers of salt with reservoir releases flows made along east-side tributaries (Quinn and Hanna, 2003; Quinn et al., 2005). RTSM is a concept that relies upon access to real-time flow and electrical conductivity data from networks of sensors located along the SJR and its major tributaries (Quinn and Karkoski, 1998). Watershed flow and water quality monitoring, modeling, salt assimilative capacity forecasting, information dissemination and sharing as part of an Environmental Decision Support System (EDSS). RTSM provides timely decision support to agricultural water districts and seasonal wetland managers - allowing them to improve the coordination of salt load export with the available assimilative capacity of the San Joaquin River (Quinn and Hanna, 2003). Although salinity management has been practiced within west-side San Joaquin River Basin agricultural water districts for more than 100 years and salinity management has only become a concern to 
seasonally managed wetlands since the announcement of the salt TMDL - progress towards RTWQM is more advanced in the wetland areas. This is largely because of the more serious long-term consequences of restricted salt export in the seasonally managed wetlands.

\section{Wetland salinity management}

Seasonally managed wetlands in the western San Joaquin Basin of California's Central Valley provide overwintering habitat for migratory waterfowl and hunting opportunities during the annual duck hunting season. Wetland water supply is supplied from the Sacramento - San Joaquin River Delta and contains inorganic salts which evapoconcentrate in the man-made, seasonally managed ponds, before being drained (between late March and early May) into channels that discharge into the San Joaquin River. This seasonal wetland drainage, produced within a 60,000 hectare wetland Grasslands Ecological Area (GEA) of the San Joaquin Basin (Figure 1) must be eliminated to preserve salt balance and sustain habitat conditions that make these wetlands the most important migratory bird resource in the western United States. Unfortunately the wetland drainage (drawdown) schedule coincides, with the germination period of salt sensitive agricultural crops, irrigated with water pumped from the River approximately $100 \mathrm{~km}$ downstream in the South Delta. Assimilative capacity, expressed in tonnes (tons) of salt, is the difference between the product of the current flow and numerical water quality objective and the current salt load measured at the compliance monitoring station. A negative River assimilative capacity (Figure 2) occurs any time the numeric water quality objective is exceeded.

Real-time salinity management (RTSM) applied to seasonal wetlands in the San Joaquin Basin requires alteration to the traditional wetland drawdown schedule. This drawdown schedule is typically established to promote the establishment of moist soil plant habitat that 
provides the optimal food resource for overwintering waterfowl. Changes to this traditional schedule come at a potential cost to the sustainability of the moist soil plant habitat resource (Frederickson and Taylor, 1982, Quinn et al. 2005). However there are few definitive studies upon which to base salinity management strategies

\section{Wetland flow and salinity balances}

Fundamental to every simulation model of flow and water quality is the concept of water and salt balance. This is a technique of conceptualizing wetland hydrology and salinity as the sum of independent processes or fluxes which can be summed together to estimate a rate of change in wetland water storage or salt content (Figure 3). Implementation of wetland RTSM will require the continuous updating of these water and salinity balances using sensors to continuously measure each component water and salt flux. Hence sensors are needed to measure water and salt fluxes into and out of each pond; the seepage flux and salt content of this flux out of the pond into the groundwater, the gain in pond water storage due to precipitation and the loss to pond water storage due to the combined fluxes from the pond to the atmosphere as a result of direct pond evaporation and moist soil plant evapotranspiration.

Sensors chosen to take these measurements should have the following capabilities :

1. Capable of accurate measurement at low flows - typical of wetland flow hydrology

2. Have a communication interface such as SDI-12 providing sensor compatibility with the data collection platform deployed

3. Fast response capable of being telemetered in combination with other sensors through the data collection platform 
4. Robust and resilient - capable of performing accurately under a wide range of environmental conditions (i.e. submerged cold winter conditions and desiccating hot summer conditions)

5. Inexpensive and easy to deploy

The environmental systems described in this paper fall into three categories :

1. Sensors that are part of a environmental sensor network that contains master (access) nodes that directly communicate with the data storage service center and slave (data) nodes that report to the master nodes. The YSI EcoNet system is an example of this environmental sensor system.

2. Sensors that are not part of a telemetered sensor network that are interrogated at irregular intervals and data is accessed manually. The Bowen weather station and the groundwater water table sensors are described as examples of this type of system.

3. Sensors that are typically deployed only once at a single location as part of a system characterization procedure or experiment. Soil salinity mapping using an electromagnetic (EM-38) sensor is described as an example of this category of remote sensing.

In the seasonal wetland application described a suite of environmental sensor systems were needed to fully characterize the ponds being monitored in order to develop accurate water and salinity balances. With over 300 wetland ponds ranging in size from a few hectares to several hundred hectares the cost of monitoring of the entire 60,000 hectare Grasslands Ecological Area basin at this level of detail would have been excessive and the scale of the data management task immense. Hence the monitoring program designed in a manner to 
provide system characterization at both the individual wetland pond scale and the wetland basin scale - with sufficient range of individual wetland pond types characterized to allow all ponds to be associated with at least one pond type. Individual wetland ponds were first characterized using the fluid electrical conductivity method, and continuously monitored during the season with a combination of water table well sensors and inlet and outlet flow and salinity sensors. A single Bowen weather station served the entire 60,000 hectare basin. Wetland basin scale monitoring was accomplished by monitoring flow and salinity in major wetland supply and drainage canals that allowed the entire basin to be subdivided into subareas that were flooded up together (source water quality was the same) and subareas that drained through a common drainage outlet. In the Grasslands Ecological Area (GEA) it was fortunate that the footprint of these flooded area sub-basins and the drainage sub-basins were mostly identical. Basin scale monitoring of major irrigation inlets and drainage outlets also provides a means of checking the lumped hydrology of the individual wetland ponds within each sub-basin.

\section{Inflow, outflow and water quality sensor networks}

In our managed seasonal wetlands application web delivery of the inflow, outflow and water quality data was YSI-EcoNet was initiated in 2005 (YSI, 2007, https://www.ysi.com/ysi ). YSI-EcoNet integrates sensor hardware (acoustic flow probes, pressure and water quality sondes) and dataloggers with software that perform local data storage, telemetry and visualization (Figure 4). YSI-EcoNet comprises a mesh of Data Nodes that collect data from flow and water quality measuring sensors and Access Nodes that have the added capability of collecting data via a low power radio interface from surrounding Data Nodes (Figure 4). 
The Access Node transmits logged data to a remote DataCenter via CDMA cellular phone or satellite modem from which the data is made accessible through the Internet. A remote data storage and processing facility - the NIVIS Data Center - maintains all data collected by the monitoring network at 15 minute intervals through a service contract with YSI Inc. The wireless mesh network topology allows "point-to-point" or "peer-to-peer" connectivity and an ad hoc, multi-hop network. The mesh network is self-organizing and self-healing - hence loss of one or more nodes does not necessarily affect its operation. This increases the overall reliability of the system by allowing a fast local response to critical events in the rare event of a communication problem. Elimination of tedious data acquisition and processing procedures through adoption of YSI-EcoNet has worked well with our wetland manager client base by eliminating much of the tedium of downloading and processing environmental data. It has also allowed wetland managers more time to perform bi-weekly sensor quality assurance checks including cleaning of sensors and checking the accuracy of staff gauge data (used in the computation of flow). Wetland managers have appreciated the time saving benefit of reviewing monitoring site data ahead of routine quality assurance checks - this helps prepare field staff for contingencies such as sensor failure prior to travelling to the site. The project monitoring sites are up to $30 \mathrm{~km}$ apart.

\section{Precipitation and evapotranspiration process sensors}

A Bowen weather station (Radiation \& Energy Balance Systems, Inc. model CR10-3C) with a continuously recording datalogger was installed centrally within the Grasslands Ecological Area in the State Wildlife Management Complex (Figure 5). The Bowen ratio-energy balance method indirectly estimates evapotranspiration (ET) (combination of direct evaporation and 
emergent moist soil plant transpiration) using micrometeorological sensors; it does not directly measure actual ET. Nevertheless, it is considered to be one of the most accurate methods for obtaining ET values if net radiation, soil heat flux, and vertical gradients of temperature and humidity can be accurately measured (ASCE 1996).

The Bowen ratio method derives from the basic surface energy balance equation:

$\mathrm{R}_{\mathrm{n}}=\mathrm{G}+\mathrm{H}+\lambda \mathrm{E}+\mathrm{W}+\mathrm{M}+\mathrm{S}$

where $\mathrm{R}_{\mathrm{n}}$ is the net radiation (incoming - outgoing), $\mathrm{G}$ is the surface soil heat flux, $\mathrm{H}$ is the sensible heat flux, $\lambda \mathrm{E}$ is the latent heat flux, $\mathrm{W}$ is the surface water heat flux, $\mathrm{M}$ is the energy flux used for photosynthesis and respiration (metabolism), and S is the energy flux into and out of plant tissue, with each term expressed in $\mathrm{W} / \mathrm{m}^{2}$. When no standing water is present, the water heat flux term can be removed. In their review of numerous ET estimation methods, Drexler et al (2004) concluded that the method can produce good results in wetlands that are relatively smooth and uniform (ie. aerodynamic resistance over the surface is not highly variable) as wellas sizeable. The sensors are powered by two 6V deep-cycle batteries, connected in series, which are continually recharged by a 53-watt solar panel. The station includes (Figure 5):

- two double-sided total hemispherical radiometers

- two vertically-separated air exchangers (automatic exchange mechanism) with temperature and humidity probes

- three soil heat flux measurement disk, soil moisture plate, and soil temperature probes

- an anemometer

- a barometer 
- a rain gauge

The net radiometers, placed at approximately $1.5 \mathrm{~m}$ above the vegetation, record both incoming and outgoing radiation to produce a single net radiation value at each time step. The air exchangers, separated vertically by a distance of $1.0 \mathrm{~m}$ and with the lower device at about $1.5 \mathrm{~m}$ above the vegetation, measured vertical gradients of temperature and vapor pressure within the equilibrium boundary layer that exists over the swamp timothy. Ground sensors were inserted into the soil at shallow depths to record heat flux, moisture, and temperature. In order to capture the "average” soil environment, sensor groups were placed in locations with slightly varying microscale moisture conditions or topography, as assessed from field observation. As a general rule, Bowen weather stations are positioned so that at least $100 \mathrm{~m}$ of upwind fetch exists for every $1 \mathrm{~m}$ of separation between the air exchangers (ASCE 1996). This helps to ensure that flux measurements represent the underlying surface and that the measured boundary layer is not contaminated by fluxes from a distant surface (Drexler et al 2004). Numerous variables influence the rate of evapotranspiration from a given surface, including solar energy, humidity, soil moisture, extent of open water, albedo, vegetation density, species composition, growth stage, heat advection, wind speed, and salinity.

Data from the weather station is recorded at 15 minute intervals and downloaded daily. Figure 5 shows the Bowen weather station with all sensors reporting to a common datalogger housed in the white, air-tight, metal enclosure. Data is downloaded to the remote project computer workstation by means of a cellular modem located within the enclosure. Upon download a series of software programs are initiated in batch to error check the data, flag outof-range or potentially erroneous values and parse the data into hourly and daily data reports. The daily mean values of wetland evapotranspiration are used in the wetland water balance. 
During wetland annual flood-up and drawdown pond surface area varies over time as the pond is being flooded or drawn down. Hence the evapotranspiration rates should be applied to the current pond surface area in order to measure the daily volume of evapotranspiration loss from each wetland pond. Detailed pond bathymetric surveys were made using an ATVmounted differential GPS instrument and relationships developed using ESRI’s Arc- GIS (3D analyst- http://www.esri.com ) to develop functional relationships between pond stage and pond surface area. Slices of a three dimensional volume rendering of each pond were made at $1 / 10^{\text {th }}$ foot $(0.03 \mathrm{~m})$ increments and the surface area and cumulative volume were recorded at each depth increment. Polynomial curves were fitted to the data to allow pond surface area to be calculated from the continuous stage data recorded at each pond outlet. Pond elevations were referenced to the deepest point in the pond which was typically the bottom of each culvert at the outlet weir box for each pond. As each wetland pond is drawn down evapotranspiration losses are the sum of direct water evaporation, evapotranspiration from emergent moist soil plants and grasses (such as cattail and skirpus) above the water surface (these losses can be less than or greater than potential evapotranspiration), direct soil evaporation and evapotranspiration from germinating grasses (such as swamp timothy and watergrass) that provide increasing soil cover as they spread and mature. Daily mean values of evapotranspiration losses are utilized in the water and salinity balance model.

\section{Groundwater water table sensors}

Monitoring of the depth to the water table below each pond is important to the estimation of water loss by the process of seepage, especially during initial pond flood-up when seepage losses can be significant. In the month of September, when wetland flood-up typically 
begins, it has been estimated that up to $30 \%$ of the applied water can be lost to seepage. Pond soils desiccate during the summer months in the San Joaquin Valley when temperatures can exceed 40 degrees $\mathrm{C}$ and crack to depths of up to $1 \mathrm{~m}$ owing to the high clay content of the soils. Water fills the cracks in the soil and the soil swells - filling the cracks and slowing down infiltration. Infiltrating water fills pore spaces causing a rise in the water table. Under some ponds, that are not subjected to regional drainage gradients - which relieve groundwater mounding below the pond - the vadose zone can become completely saturated. Pond seepage can be estimated by the rate of rise of the water table using estimates of shallow aquifer porosity.

Schlumberger Diver pressure sensors (http://www.swstechnology.com/equipment product.php?ID=5) were attached to $4 \mathrm{~m}$ lengths of plastic-coated cable and fixed to the well cap of each monitoring well (Figure 6). Although technology exists to telemeter the pressure and temperature data that are produced by each sensor - the fact that groundwater levels change slowly and incrementally over time - made it more cost effective to make periodic downloads of the data during each field site visit. RTSM, which is concerned with wetland drawdown and drainage volumes, is not impacted by changes in water table - however these data are critical for estimates of annual water and salt balances.

\section{Mapping of wetland soil salinity using electromagnetic sensors}

Remote sensing of wetland soil salinity content is being used as an indirect check on wetland salt balance - and to assess the distribution of salts within each wetland pond. Ponds managed for swamp timothy production (the most productive of the moist soil plants used to 
provide waterfowl habitat) are typically drawn-down in mid-March - a schedule that appears to favour swamp timothy dominance. Real-time water quality management would likely require the wetlands to be drained later, in mid-April, since San Joaquin River assimilative capacity is higher during this period when major releases are made from east-side reservoirs to aid fish migration. The impacts of a delayed drainage hydrology on the ecological health and productivity of these wetlands as a food source for migratory waterfowl are not clear although experience suggests a shift from swamp timothy dominance to water grass is the most likely long-term outcome. The warmer temperatures in April result in increased pond evaporation which produce higher concentrations of salts in those ponds still inundated. Higher concentrations of salt in the water column will affect soil salinity as saline water infiltrates or diffuses into the wetland soil.

An electromagnetic sensing instrument (EM-38 Geonics Ltd. - http://www.geonics.com ) was used to estimate bulk soil salinity in the wetland ponds (Figure 7). The EM-38 instrument utilizes dual coil electromagnetic induction to obtain a signal response which is a function of both bulk soil salinity and soil moisture content. When water content is controlled - the instrument can be used to map near-surface soil salinity. The EM-38 can be used in two different orientations; vertically or horizontally. The peak signal strength for the horizontal and vertical orientations are between $0-0.3 \mathrm{~m}$ and $0.3-0.6 \mathrm{~m}$ respectively. Software has been developed by the US Department of Agriculture Salinity Laboratory (ESAP http://www.ars.usda.gov/Services/docs.htm?docid=8918 ) to convert the raw EM-38 signal to electrical conductivity (EC) after soil cores have been drawn and the saturated soil extract salinity determined at sample sites chosen by the program to conform to a normal distribution within each pond.. The EM-38, along with a backpack GPS system (Trimble Inc.www.trimble.com) was connected to a hand-held PC (Juniper Systems, Allegro Cx - 
http://www.junipersys.com/products/products.cfm?id=99). Data logging was performed with the aid of TrackMaker software (http://www.kdjonesinstruments.com/uploads/files /pdfs/TrackMaker31.pdf) which helps the field analyst visualize each transect of the field survey, which can be performed by foot or GPS-enabled ATV. The EM-38 instrument has been widely used to assess soil salinity in agricultural areas (Corwin and Lesch 2003, 2005a, and 2005b, Isla et al. 2003, Lesch and Corwin 2003, Lesch et al 2005, Cassel 2007) though its use in wetland soil applications has not been reported. Factors to be considered in wetland soil salinity remote sensing include variations in soil texture and taxonomy, soil moisture, topography, vegetation and litter cover which all affect electromagnetic response (Hanson and Kaita 1997, Suddeth et al. 2005, Brevic et al. 2006).

The instrumentation used in the field survey and its deployment is shown in Figure 7. The right-hand panel in Figure 7 shows the individual survey points along each transect for two adjacent wetland ponds. Readings were taken every 2 seconds and the transects were spaced approximately 5 meters apart. The results of the survey of the Ducky Strike Duck Club south pond (one of twenty four ponds surveyed) is shown in Figure 8. The data shown is the raw sensor data from the EM-38 instrument prior to filtering based on the regression model between laboratory saturated extract soil salinity and field EM readings at the control sites within each pond. Figure 8 also shows the frequency distribution of salinity measurements over the wetland area and the control measurements made at selected sample sites to represent the full range of salinity measurements.

Data collected over a period of 3 years for ponds subjected to late wetland drawdown has shown a statistically significant increase in soil salinity due to the practice of delayed wetland drawdown in those ponds subjected to the highest influent salinity concentration. Water delivery to ponds in the Southern Division of Grassland Water District are typically higher in 
EC than those northern Division owing to the fact that the Northern Division receives water supply closer to the pumping source than the Southern Division. Evapoconcentration of salts leads to higher soil concentrations in those areas where influent salinity is highest. This also suggests that adoption of RTSM should consider rotating a particular wetland back to a more traditional hydrology in instances where influent salinity is elevated.

\section{Data quality control and assurance of continuous data}

A common weakness of many environmental decision support projects that rely on the telemetry of continuously monitored data is data quality assurance. Data quality assurance is easier to provide for discrete or periodic monitoring where adequate time exists between sample collection events to analyze data and make corrections to the instrument software, in the case of sensor drift, or replace a sensor in the case of irreversible sensor failure. Data quality assurance protocols established for discrete environmental sampling are well established and data quality control plans are integral components of most environmental monitoring projects. However with continuously recorded and reported data - the logistics of monitoring site visitation, data management, processing and error correction become more onerous. Until recently few software tools existed to facilitate and guide these tasks - even the idea of migrating preliminary environmental data to another internet-accessible location after data quality assurance had been performed has not been routinely practiced. Inaccurate or absurd data posted to a project website can cause irreparable harm to a project and can quickly lead to a loss of confidence in the stakeholder community. In our wetland salinity management project cumulative flow calculations which were performed by our acoustic Doppler instrument were accurate when downloaded from the data collection platform but 
were 100 times too high when transmitted using the SDI-12 protocol to an external datalogger. This turned out to be a programming error in the firmware $-\mathrm{a}$ decimal point was omitted in the program and re-inserted during output processing. This error was caught by one of our project cooperators, who had become a routine user of project real-time data. Our close working relationship prompted early feedback from this cooperator and relatively quick recognition and resolution of the problem. This is not typical - problems such as these often fester within the stakeholder community before coming to light - by which time enthusiasm for the project and trust between project proponents and the stakeholder community has been eroded.

\section{Software tools for continuous data quality assurance}

The Aquarius Environment Toolbox (Aquatic Informatics, Inc., 2009) is a suite of software object modules used to manage the entire data processing workflow from the project flow and water quality monitoring stations. The software object modules relevant to the wetland salinity management project include those responsible for: Data Pre-Processing; Data Correction; Modeling; and Output Visualization and Reporting. The Aquarius Whiteboard environment is used to assemble the sequence of object modules that comprise the data processing workflow (Figure 9).

The Data Pre-Processing module comprises software objects for Signal Joining and Signal Trimming. The Signal Joining object is used to append multiple time series data files during each data download so that a complete data record can be compiled within a local database. Storing the data in a local database after performing data quality assurance allows the certified data to be uploaded routinely to the NIVIS Data Center, which previously provided 
access to uncensored real-time data. The Signal Trimming object is used to trim outliers and periods of incomplete data records from the data record before being stored in the database. At the beginning of the project technical problems such as bad circuit boards and poorly sealed acoustic Doppler sensors produced periods of incomplete or suspect records which had to be removed from the data record.

The Data Correction object is used to apply manual adjustments to time series datasets. Autonomous collection of data results in anomalies such as biases, drifts, outliers, and nonphysical data. Hence, the Data Correction object is used to apply corrections for sensor drift (not typically a problem with the water quality (YSI) or acoustic Doppler (MACE) instruments) or sensor fouling (a significant problem in the wetland environment of the project). For example a Fouling Drift correction is used routinely to compensate for biological fouling or scaling of the water quality sensor that tend to skew readings in a progressive fashion as the biological film or scale develops. Standard practice for quality assurance is to take a single measurement from a sensor immersed in a control solution both before and after cleaning. A more time and cost effective protocol, practiced in the current project, was to calibrate a portable YSI sonde (comprising EC, temperature and pressure sensors) in the laboratory before and after each day in the field. Then the sonde at each monitoring site was calibrated to the ambient portable sonde sensors readings reading at each monitoring site. The sonde EC sensor was recalibrated if the readings differ from the value of the standard solution. Pressure transducers in both the water quality sonde and acoustic Doppler instrument remained stable requiring little adjustment. Monthly removal of biological growth surrounding the pressure transducers was sufficient to keep the transducers from drifting - except in the instances of catastrophic failure where improper sealing with epoxy allowed moisture migration into the sensor. 
When using the Aquarius software each correction made to the time series data is recorded in the Correction History Manager which logs information about the correction and makes an entry in the correction history (Aquatic Informatics, 2009). Comments describing the correction appear in small text that is auto generated and can be modified, if necessary, to increase the amount of information for a subsequent correction audit. Offset adjustments were made to correct for a constant (throughout time) bias in the target time series data. Offset adjustments were necessary when a sonde had to be replaced or a sonde moved higher within the stilling well as a result of sediment accumulation around the base of the stilling well. This accumulation of sediment affected water circulation around the electrical conductivity and temperature sensors. Within the Aquarius software the Mark Region tool is used to select a section of the target time series where the offset correction can be used to adjust readings upwards or downward. The percent correction feature in the correction control pane of the software allows the user to apply a calculated known percentage correction to the signal at either the beginning of the data sequence or at the end. Data outliers can be removed using these tools and short data gaps can be interpolated without resorting to a model based correction approach. Data gap interpolation controls provide options that include the application of a linear spine, which simply draws a straight line in between the endpoints of the gap or a cubic spline, which uses up to 5 data points outside the range of the marked gap to guess at the curvature of the time series and using a best-fit curved line. The automated interpolation control options within the Aquarius toolbox are a significant technical advance over existing software and are critical for the anticipated expansion of existing sensor networks necessary to fully implement RTSM. Manual as well as automated interpolation changes are all noted in the Correction History Manager. Each time a correction is applied to a section of target time series data the Correction History 
Manager is invoked to capture details about the user performing the correction and the rationale for performing the correction.

The Modeling object within the Aquarius toolbox has proved useful in the application of calibration factors to discharge data derived from acoustic Doppler velocity and pressure sensors. Acoustic Doppler velocity sensors sample the flow volume either approaching or moving away from the sensor. In open channels with fluctuating stage or in culverts which can flow partially full - it is difficult to obtain a true mean area-velocity owing to the friction along the perimeter of the conveyance structure. Flow rating relationships between reported and actual flow have been developed for each monitoring site and the rating equation built into the modeling object to transform the reported flow value to an actual flow. At a number of monitoring sites weir boards (flash board risers) provide the means of controlling wetland pond stage and pond outflow - at these sites the modeling object was first used to calculate discharge using the weir equation which is a function of board width and height and water stage over the weir boards. However the difficulty of maintaining continuous records of weir board adjustments proved too onerous for wetland managers and became a bottle-neck for real-time data reporting. Acoustic Doppler flow sensors were retrofitted at each wetland drainage site to address this issue.

The Aquarius toolbox contains a full suite of Output Visualization and Reporting tools that allow easy review and auditing of any data sequence within the time series database at each monitoring site. The Quick View object displays time series data in a spreadsheet format which facilitates plotting and charting and can be used to provide descriptive statistics of each sensor time series record. It has been used to create overlay multiple data traces within a 
single window in order to check the functioning of suspect sensors in the monitoring network as part of the data quality assurance program. Reporting the quality certified data back to the NIVIS website (Figure 10) was a feature initially lacking in the commercial release of YSI EcoNet.

The NIVIS Data Center did not permit client access to the data except as served through the NIVIS EcoNet website - rather the Data Center provided a means of discriminating between public and private (password protected) access to the website. This had the unfortunate consequence of restricting public access to current data only, given our cooperators reluctance to share potentially flawed data with the general public, as discussed at the beginning of this paper. Only project personnel and cooperators were provided with private user access allowing these clients to download the time series data record. In late 2009 a solution was negotiated between YSI Inc. and the NIVIS Data Center that provided a data export wizard and the ability to add a second data column paired with each of the webreported sensor outputs. The schema for the protocol appears in Figure 10. Under this protocol public access clients can view all historic data once they have been migrated into the second column after having undergone data quality assurance procedures.

Private access clients are able to view both columns of data on the project website and have full access to the time series data for all monitoring sites. Automation of the data filtering and web posting process will speed-up stakeholder access time to information needed to make RTWQM decisions. These actions will help develop the assurances needed for stakeholders to fully implement RTWQM within the San Joaquin River Basin. 


\section{Water quality forecasting and decision support}

Successful implementation of RTSM in the San Joaquin Basin requires that salt loads exported from managed wetlands and other west-side dischargers within the Basin never exceed the calculated assimilative capacity of the San Joaquin River. River assimilative capacity (expressed as a salt mass load) is determined by the product of river flow and the ambient water quality standard for salinity, established at the downstream compliance monitoring station. A decision support tool was developed to simulate daily river assimilative capacity and permit forecasting of allowable salt loading from managed wetlands in the Basin based on real-time flow and salinity data.

The Watershed Management Framework (WARMF) model (Chen et al. 2001, Herr et. al, 2001, Herr and Chen, 2006) is comprehensive decision support tool specifically designed to facilitate TMDL development at the watershed-level. The WARMF-SJR application simulates the hydrology of San Joaquin River Basin and performs mass balances for a broad suite of potential contaminants including total dissolved solids. The model simulates tributary inflows from the major east-side rivers, agricultural and wetland drainage return flows, riparian and appropriative diversions and uses hydrologic routing to calculate flow and water quality at approximately $1 \mathrm{~km}$ intervals along the main stem of the SJR. Wetland drainage from the Grassland Ecological Area was partitioned into component State, Federal and private wetland contributors to SJR salt load. A GIS-based graphical user interface (GUI) facilitates the visualization of model input flow and water quality data. Data templates expedite automated data retrieval from State and Federal agency hydrology and water quality 
databases and the automated updating of model input files. Water managers can enter daily schedules of diversions and discharges using the spreadsheet formatted model data interface. Standardized model output graphics aid the dissemination of flow and water quality forecasts.

A wetland water quality model is under development that simulates water and salinity balances for individual (and lumped) ponded areas and which aggregates wetland discharge and salt loading from all contributing areas and enables comparison with, yet to be established, salt loading targets for the Grasslands Ecological Area. Monthly sub-basin, seasonally-adjusted salt load targets are one of a number of salinity management strategies that could be used to encourage cooperation and coordination of wetland drawdown by State, Federal and private wetland stakeholders. Coalition building between stakeholders with like interests and who are required to comply with similar environmental regulations has been effective in California as a means of retaining local control and management flexibility. The WARMF model is used as the general simulator for the wetland decision support system application. http://www.epa.gov/ATHENS/wwqtsc/html/warmf.html . The new model application will track the salt concentration within each ponded area based on estimated wetland evaporation, seepage and cumulative inflow and outflow and the salinity concentrations of these fluxes. Output from the WARMF wetland model application will overwrite estimated values for the State, Federal and private wetland salt loads in the WARMF-SJR model - to provide a more accurate assessment of San Joaquin River assimilative capacity.

\section{Institution building}


Realization of the potential of RTSM will require the formation of a watershed-level salinity management entity with the authority to encourage compliance with sub-basin salt load targets and to impose penalties for violation of these established salt load limits. A local coalition of entities discharging drainage to the San Joaquin River formed a "Drainage Authority” to coordinate flow and water quality monitoring requirements imposed by the Regional Water Quality Control Board (a State institution responsible for implementation of TMDL's in the San Joaquin River Basin). This Drainage Authority is financed by stakeholder contributions and retains a staff to oversee the activities of the agricultural, wetland and municipal dischargers of salt and other contaminants into the San Joaquin River. Oversight involves maintenance of monitoring stations, responsibility for discrete sample collection and analysis and monitoring data record keeping. Implementation of RTSM will require a similar institution though with added responsibilities of coordinating both drainage return flows and reservoir releases from east-side tributaries, synthesis of real-time data and dissemination of daily salt assimilative capacity forecasts for the San Joaquin River. At the present time a conceptual conceptual design of this new institution has not been formulated.

\section{Summary}

Technical advances in data acquisition and information dissemination technologies have made possible the implementation of a RTSM program in California's San Joaquin Basin wetlands. RTSM relies on continuously recording sensors that form the backbone of a monitoring network and simulation models that are used to forecast flow and water quality conditions in the receiving water body and the tributary watersheds that contribute flow and salt load to the river. The application discussed in this paper - RTSM of drainage from 
seasonal wetlands - relies on a suite of sensor technologies the data from which are used to develop water and salt mass balances. The concept of mass balance is fundamental to all flow and water quality simulation models. Models can also be used to extrapolate the results of system monitoring since it is impossible to collect data for every point and non-point source of a pollutant in the Basin. This paper has described the use of several state-of-the-art sensor technologies that are being combined with more traditional sensor techniques to support RTSM. The paper also discussed the problems associated with continuous data quality assurance and described a new software product which streamlines the process of data error correction and dissemination that will be necessary to build stakeholder assurances key for successful implementation of the RTSM in the GEA.

\section{Acknowledgements}

This work was financially supported by the California State Water Resources Control Board, the U.S. Bureau of Reclamation Science and Technology Program and the California Department of Water Resources and partially supported by the U.S. Department of Energy and LBNL under Contract No. DE-AC02-05CH11231. The authors wish to thank the US Bureau of Reclamation, California Department of Water Resources and California Regional Water Quality Control Board for their funding of associated research projects over the past decade - directed at implementing RTWQM in the San Joaquin Basin of California. Thanks also to the Grassland Water District and California Department of Fish and Game hosted the current projects within the Grasslands Ecological Area. YSI Inc. has provided valuable technical support for deployment of the YSI-ECONET technology in California. 


\section{References}

Aquatic Informatics Inc. info@aquaticinformatics.com Aquarius Hydrologic Workstation software. 200 - 322 Water St., Vancouver, B.C. V6B 1B6, Canada.

Brevik, Eric C., T.E. Fenton, A. Lazari. 2006. Soil electrical conductivity as a function of soil water content and implications for soil mapping. Precision Agriculture. 7: 393-404.

California Irrigation Management Information System : Site Information for CIMIS Stations : http://www.cimis.water.ca.gov/cimis/infoStnSiting.jsp

Cassel, F.S. 2007. Soil Salinity Mapping using ArcGIS. In GIS Application in Agriculture, Chapter 8, pg 141-162. Francis J. Pierce and David Clay ed. CRC Press, New York.

Corwin, D.L. and S.M. Lesch. 2003a. Application of Soil Electrical Conductivity to Precision Agriculture: Theory, Principles, and Guidelines. Agronomy Journal. V.95, no. 3.

Corwin, D.L., S.M. Lesch, P.J. Shouse, R. Soppe, J.E. Ayars., 2003b. Identifying soil properties that influence cotton yield using soil sampling directed by apparent soil electrical conductivity. Agron. J. 95 (2), 352-364.

Corwin, D.L. and S.M. Lesch. 2005a. Characterizing soil spatial variability with apparent soil electrical conductivity. Computers and Electronics in Agriculture 46:103-133.

Corwin, D.L. and S.M. Lesch. 2005b. Apparent soil electrical conductivity measurements in agriculture. Computers and Electronics in Agriculture 46: 11-43.

Drexler J.Z., R.L. Snyder, D.Spano and K.T. Paw. 2004. Hydrol. Process. 18, 2071-2101 (2004) 
Environmental Protection Agency, 2002. Total Maximum Daily Load for Salinity and Boron in the Lower San Joaquin River. Staff report by the Regional Water Quality Control Board, Central Valley Region, California.

Chen, C.W., J. Herr, J., and L.H.Z. Weintraub. 2001. "Watershed Analysis Risk Management Framework: Update One: A Decision Support System for Watershed Analysis and Total Maximum Daily Load Calculation, Allocation, and Implementation,” EPRI, Palo Alto, CA. Topical Report 1005181.

Fredrickson, L.H. and T.S. Taylor 1982. Management of seasonally flooded impoundments for wildlife. Resource Publication 148. U.S. Dept. of the Interior, Fish and Wildlife Service, Washington, D.C.

Hanson, B.R., and K. Kaita. 1997. Response of Electromagnetic Meter to Soil Salinity and Soil-Water Content. Journal of Irrigation and Drainage Engineering March/April: 141143.

Herr, J., L.H.Z.,Weintraub, and C.W. Chen. 2001. "User's Guide to WARMF: Documentation of Graphical User Interface,” EPRI, Palo Alto, CA. Topical Report.

Herr J. and C.W. Chen. 2006. San Joaquin River Model : Calibration Report. CALFED Project ERP-02D-P63 Monitoring and Investigations for the San Joaquin River and Tributaries Related to Dissolved Oxygen. Systech Water Resources Inc. San Ramon, CA.

Isla, R., R. Aragues, and A. Royo. 2003. Spatial variability of salt-affected soils in the middle Ebro Valley (Spain) and implications in plant breeding for increase productivity. Euphytica 134: 325-334. 
Lesch, S.M., D.L. Corwin, D.A. Robinson. 2005. Apparent soil electrical conductivity mapping as an agricultural management tool in arid zone soils. Computers and Electronics in Agriculture 46: 351-378.

Lesch, S.M., and D.L. Corwin. 2003. Using the Dual-Pathway Parallel Conductance Model to determine how different soil properties influence conductivity survey data. Agronomy Journal 95:(395-379).

MACE USA LLC. http://macemeters.com/ P O Box 7144 Shawnee Mission - Kansas City Kansas 66207.

McNeill, J.D., 1980. Electromagnetic Terrain Conductivity Measurement at Low Induction Numbers. Tech. Note TN-6. Geonics Limited, Ontario, Canada.

Mushet, D.M., N.H. Euliss, Jr., and S.W. Harris. 1992. Effects of Irrigation on seed Production and Vegetative characteristics of Four Moist-Soil Plants on impounded Wetlands of California. Wetlands, Vol. 12, No. 3. December, pp. 204-207.

Quinn, N.W.T. and W.M. Hanna, 2003. A decision support system for adaptive real-time management of seasonal wetlands in California. Environmental Modelling and Software, Volume 18, Issue 6, pp. 503-511

Quinn, N.W.T. and J. Karkoski, 1998. Real-time management of water quality in the San Joaquin River Basin, California. American Water Resources Association, Vol. 34, No. 6.

Quinn N.W.T., J.S. Hanlon, J.R. Burns, C.M. Taylor, T Lundquist and W.T. Stringfellow. 2005. Real-Time Water Quality Monitoring and Habitat Assessment in the San Luis 
National Wildlife Refuge. Lawrence Berkeley Laboratory Topical Report \# 58813, Berkeley, CA.

Quinn, N.W. T., and W.M. Hanna. 2002. "Real-Time Management of Seasonal Wetland Drainage as an Alternative for Compliance with Salinity TMDL Objectives in California’s Grasslands Basin”. Presentation given at the Agricultural TMDL conference Helping Irrigated Agriculture Adjust to TMDLs hosted by the United States Committee on Irrigation and Drainage Water Management and the Association of California Water Agencies, Sacramento, California, October.

Quinn, N.W.T. and W.M. Hanna. 2003. A Decision Support System for Adaptive RealTime Management of Seasonal Wetlands in California. Environmental Modelling and Software 18(503-511).

Radiation and Energy Balance Systems, Bowen Ratio Energy Balance Station,. Bellvue, WA, 2004.

Reinecke, K.J. and K.M. Hartke. 2005. Estimating moist-soil seed available to waterfowl with double sampling for stratification. Journal of Wildlife Management 69(2):794-799.

Rhoades, J.D., N.A. Manteghi, P.J. Shouse, and W.J. Alves. 1989. Soil electrical conductivity and soil salinity: New formulations and calibrations. Soil Science Society of America Journal 53:433-463.

Suddeth, K.A., N.R. Kitchen, W.J. Wiebold, W.K. Batchelor, G.A. Bollero, D.G. Bullock, D.E. Clay, H.L. Palm, F.J. Pierce, R.T. Schuler, and K.D. Thelen. 2005. Relating apparent electrical conductivity to soil properties across the north-central USA. Computers and Electronics in Agriculture Vol. 46, issue 1-3, pg 263-283. 
Taft, Oriane W., Mark A. Colwell, Craig R. Isola, and Rebecca J. Safran. 2002. Waterbird responses to experimental drawdown: implications for the multispecies management of wetland mosaics. Journal of Applied Ecology 39:987-1001.

U.S. Fish and Wildlife Service. 1986. North American Waterfowl Management Plan. U.S. Fish and Wildlife Service, Portland, Or.

Williams, B.G., Hoey, D., 1987. The use of electromagnetic induction to detect the spatial variability of the salt and clay contents of soils. Aust. J. Soil Res. 25, 21-27.

Yellow Springs International Inc. 2007. https://www.ysi.com/ 1700/1725 Brannum Lane Yellow Springs, OH 45387-1107, USA. 


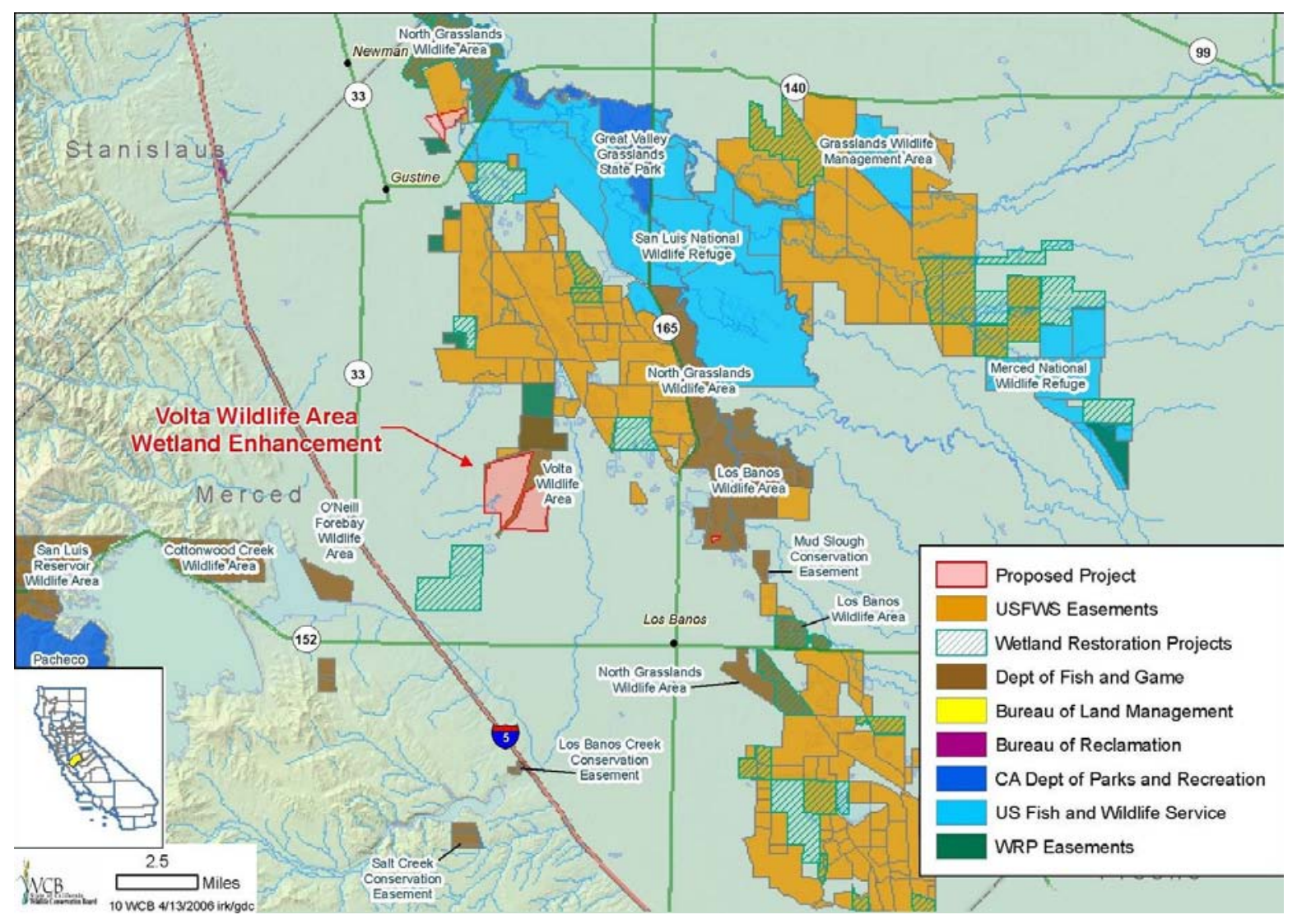

Figure 1. Project area which contains approximately 60,000 hectares of seasonal wetland habitat collectively known as the Grasslands Ecological Area (GEA). It comprises Federal, State and private wetlands and conservation easements to form the largest contiguous area of waterfowl habitat in the western United States. The GEA is subject to EPA mandated salinity regulation which is best met through an innovative salt management technique, now under development, known as real-time salinity management (RTSM). 


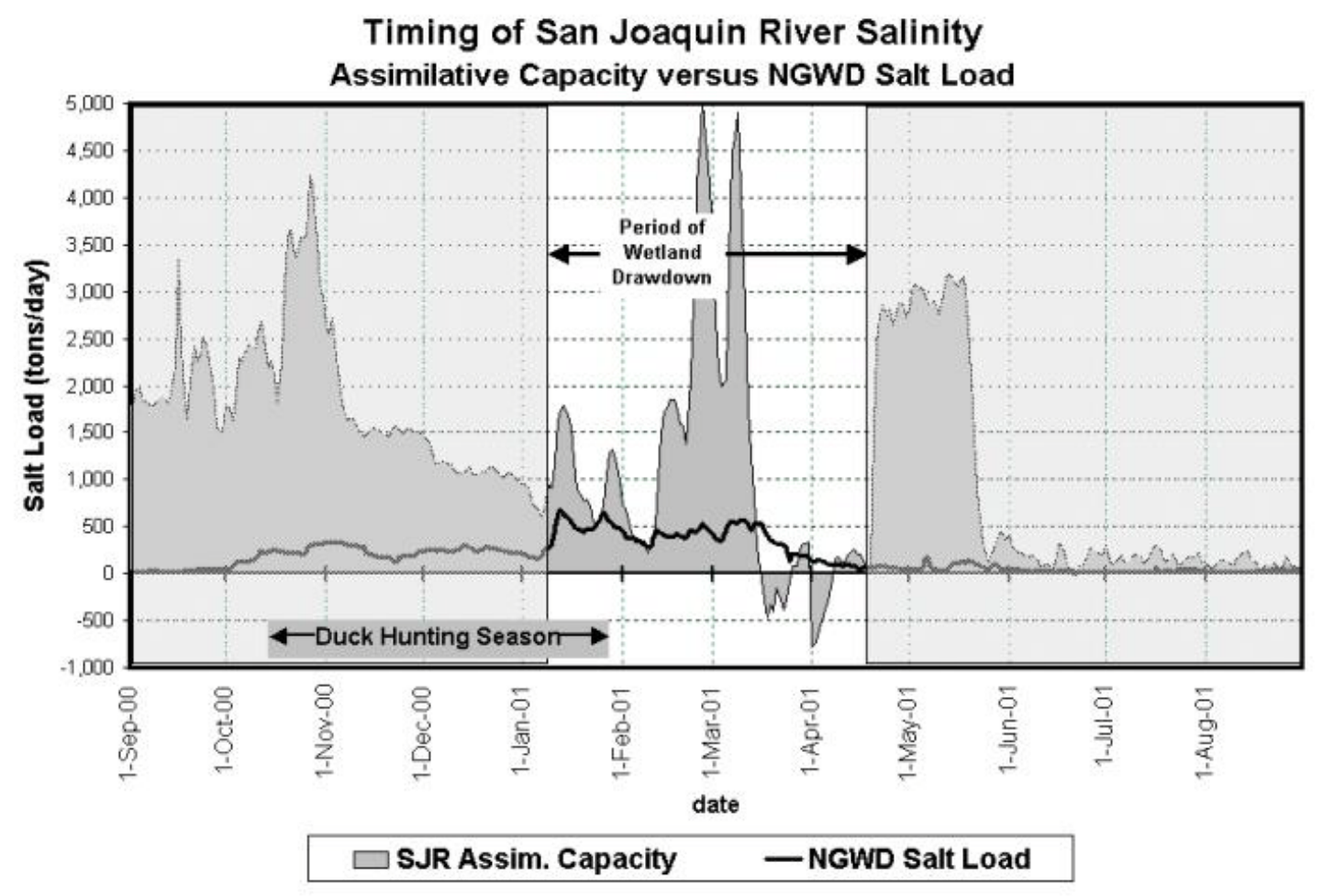

Figure 2. Illustration of the concept of RTSM. Salt assimilative capacity (shown by the shaded grey area - tons/day) is typically high during winter months when a combination of a higher salinity river objective $(1,000 \mathrm{uS} / \mathrm{cm})$ and rainfall runoff produce high diluting flows from east-side San Joaquin River tributaries. Wetland drainage salt loads from private wetlands in the Grasslands Ecological Area are sufficient to produce negative assimilative capacity during periods in late March and early April when river salt concentrations exceed State-mandated water quality objectives. Under a RTSM scenario delaying wetland drainage drawdown until mid-April would re-schedule this salt loading to a period of high River assimilative capacity preventing exceedence of river salinity objectives. 


\section{Wetland Water Quality Model}

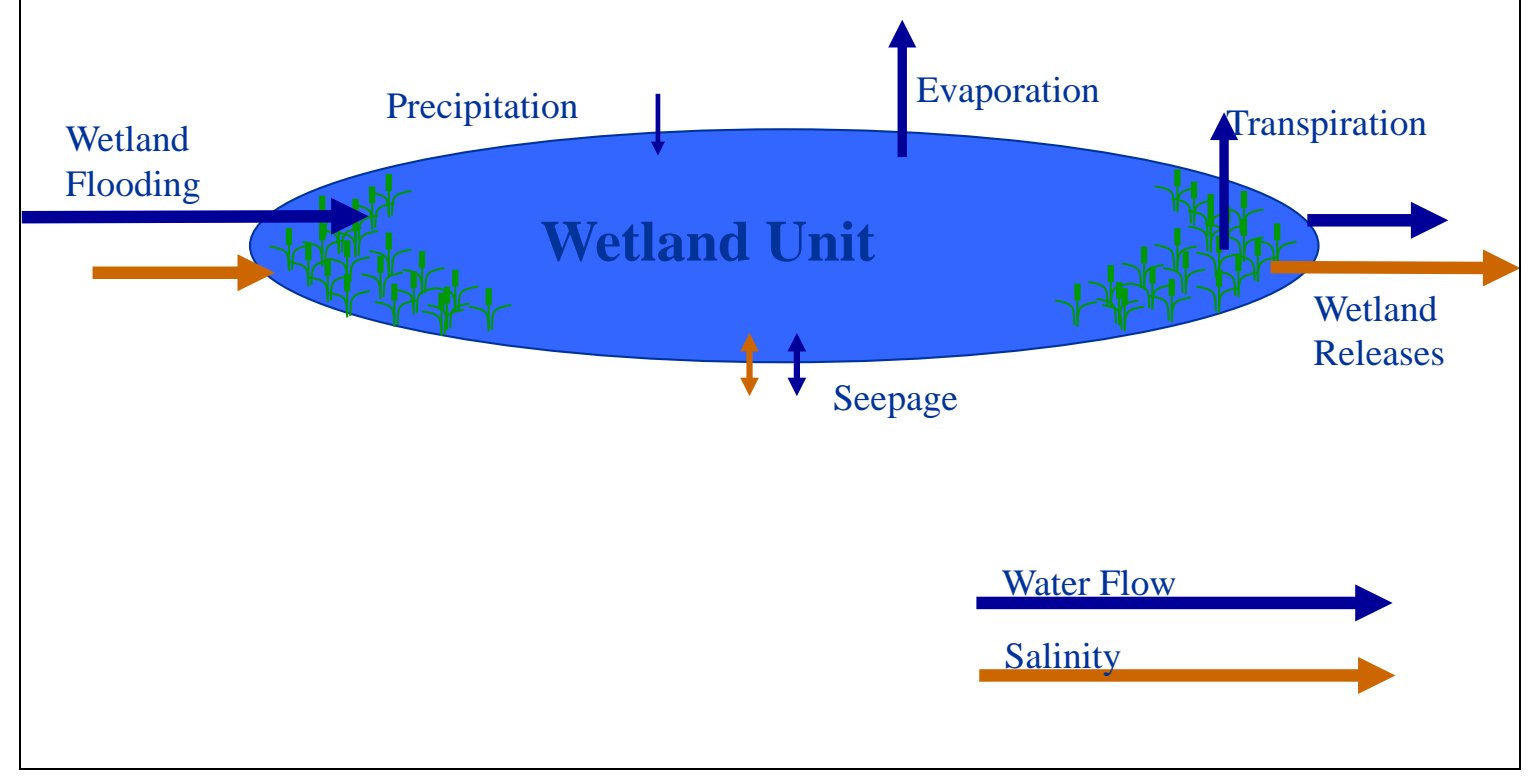

Figure 3. Conceptual wetland hydrology and salinity model showing component processes. 


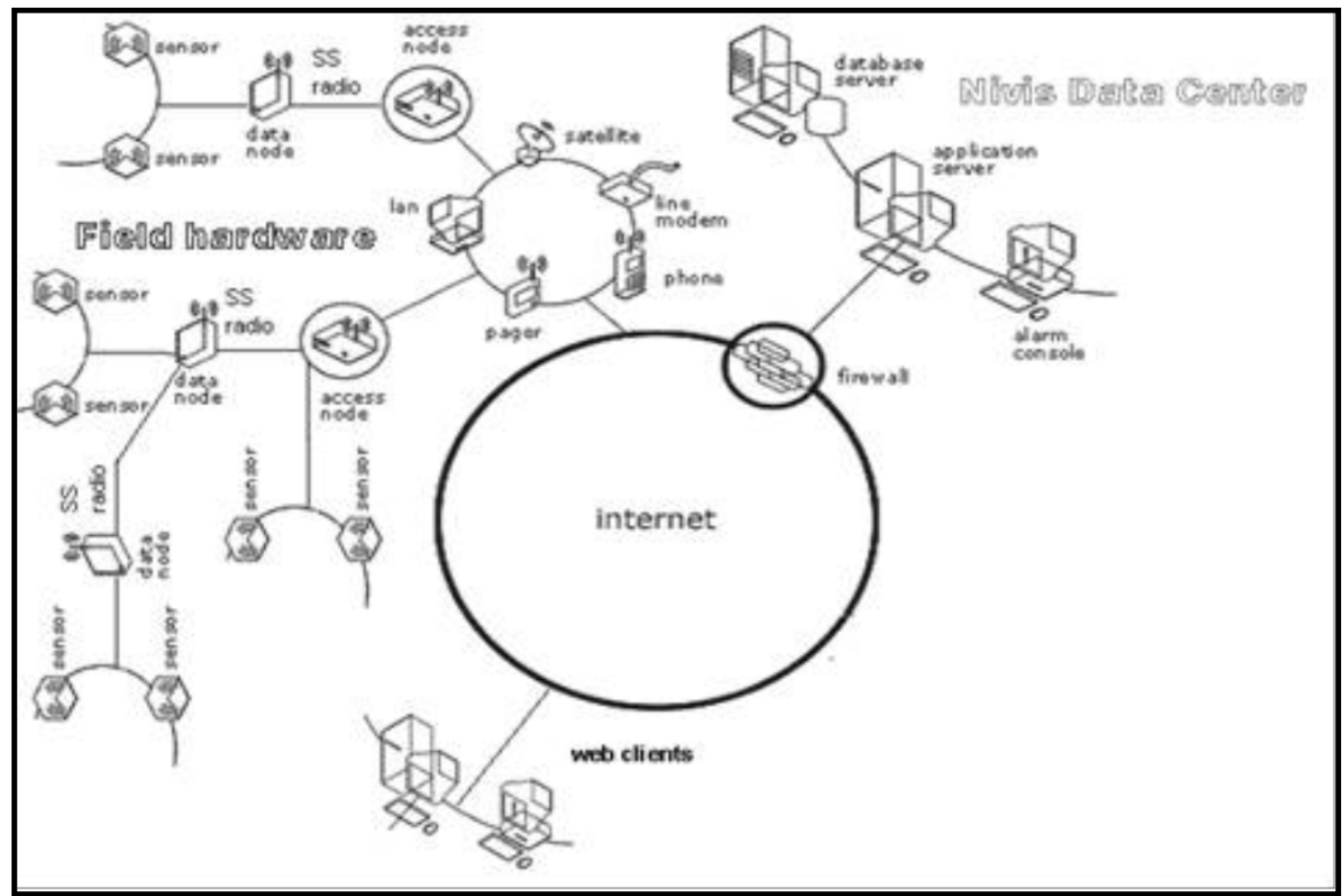

Figure 4. Environmental sensor network showing how individual sensors at each monitoring site report to local data nodes and communicate to each other through radio frequency telemetry. Master (access) nodes poll each data node and report data from multiple data nodes to the NIVIS data center. The NIVIS Data Center posts sensor data every 15 minutes to the web - allowing near real-time retrieval of preliminary data. Continuous data processing is required to produce data suitable for public access and retrieval (YSI Inc., 2007). 


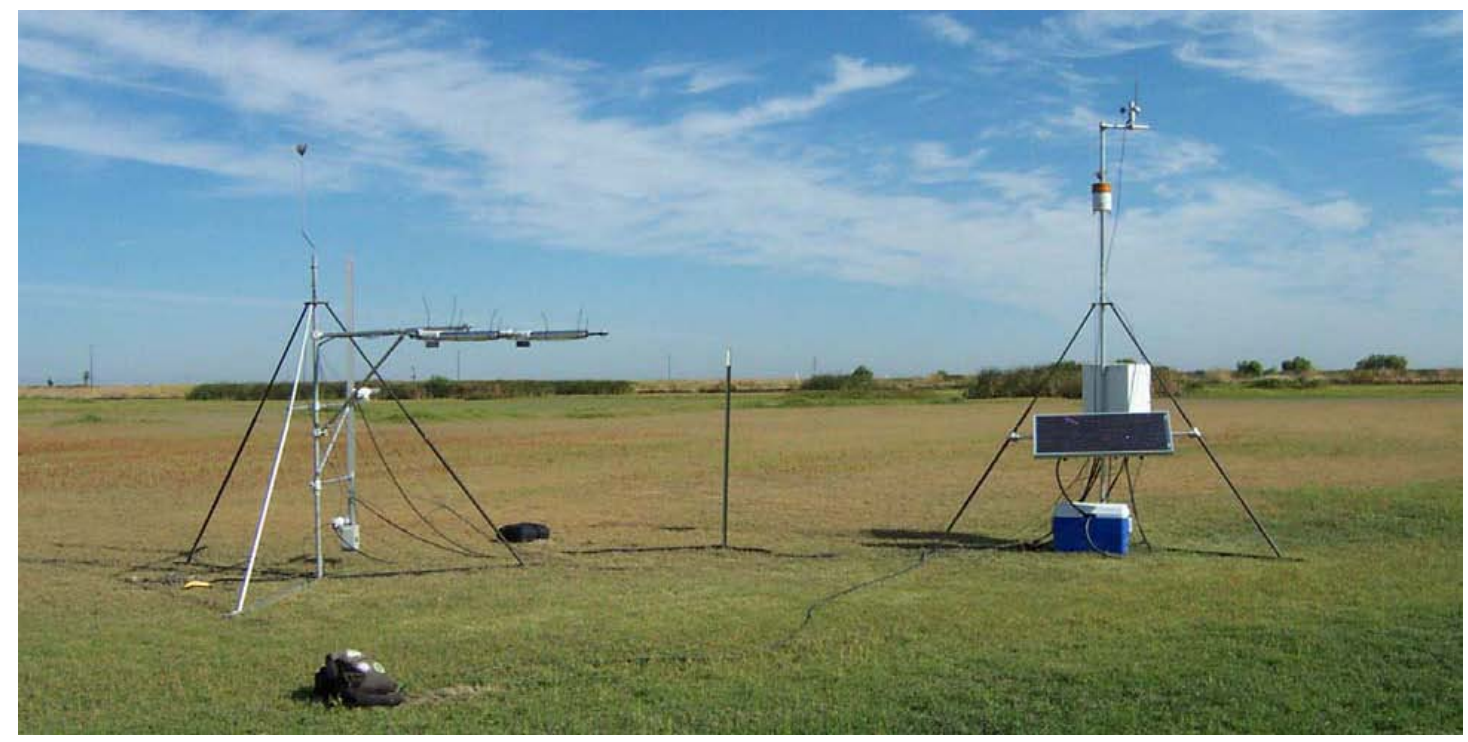

Figure 5. Bowen weather station showing the solar panel, 6V batteries (inside the cooler below to prevent contact with moisture), cable box with datalogger, rain gauge, and anemometer. Two net radiometers (left side of photo) are held at approx. $1.5 \mathrm{~m}$ over the surface. The air exchangers (right side of photo) face the prevailing winds and are spaced $1 \mathrm{~m}$ apart, with the lower exchanger positioned approximately $25 \mathrm{~cm}$ above the surface. 


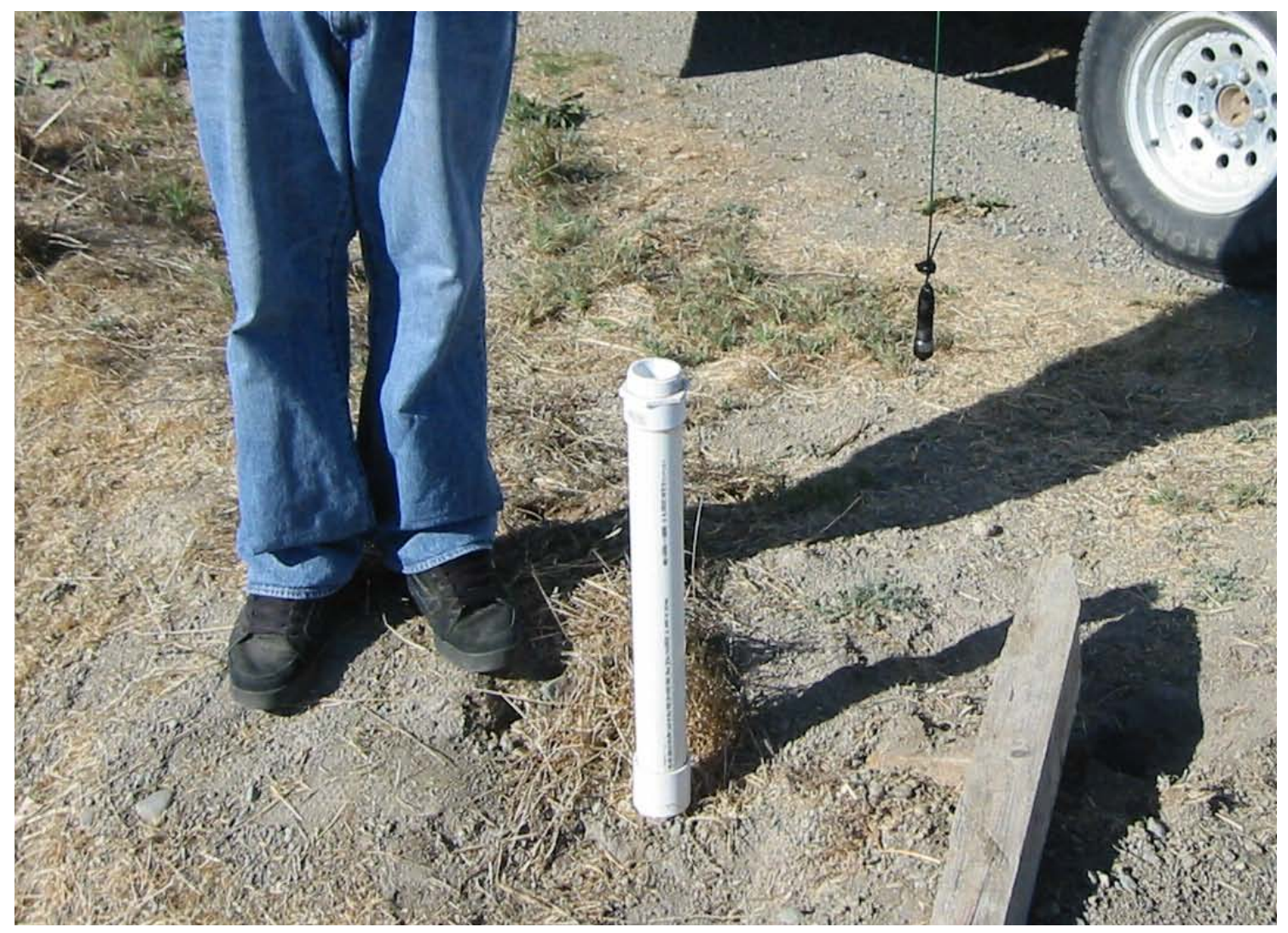

Figure 6. Deployment of pressure sensors in shallow groundwater monitoring wells to measure changes in water table depth and to estimate pond seepage losses during fall floodup. 


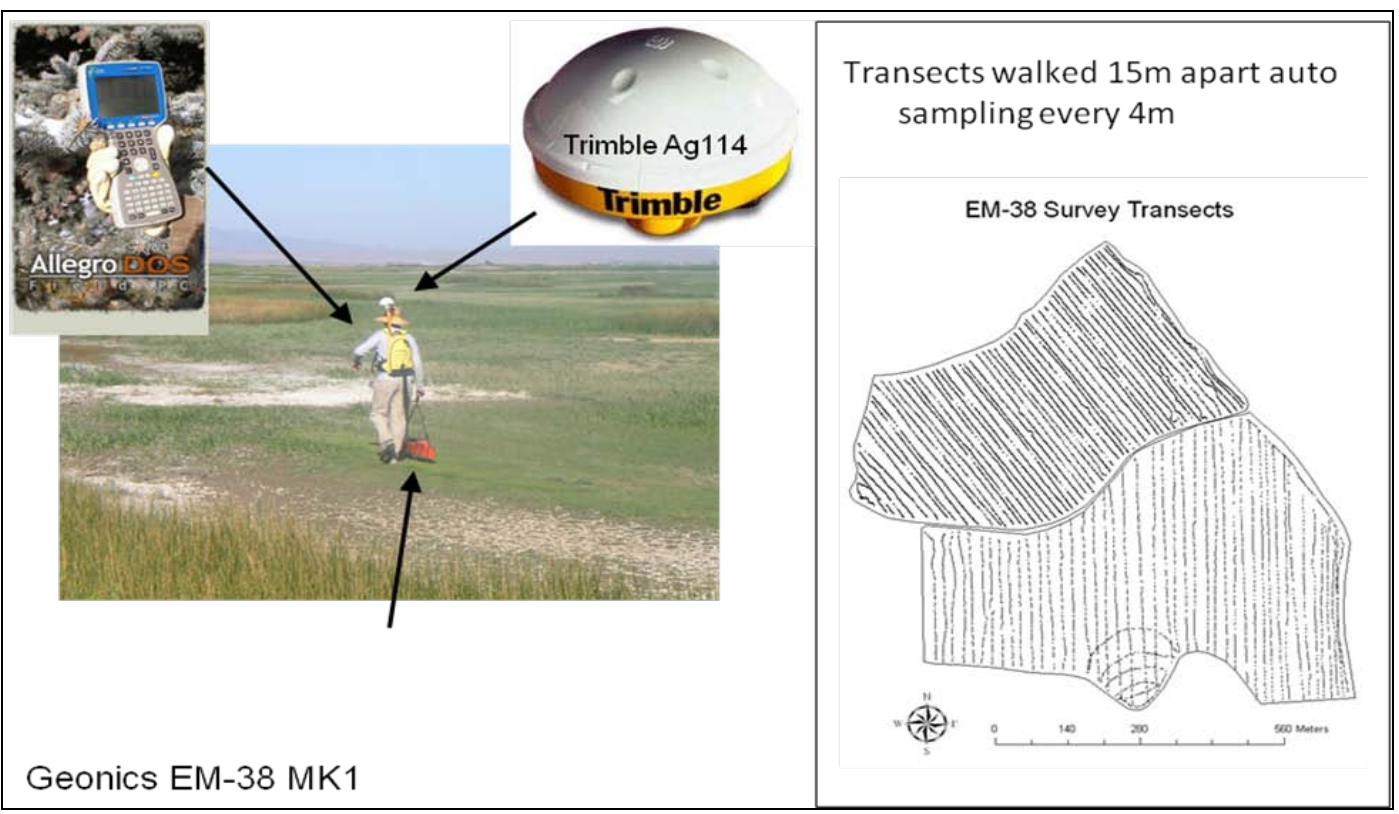

Figure 7. Instruments used to perform soil salinity mapping of wetland soils in the Grasslands Ecological Area. Image shows the field analyst traversing a large area of swamp timothy, a non-native grass that is nevertheless regarded as highly desirable as waterfowl habitat. A patch of salt efflorescence appears in front of the field analyst - high soil salinity limits moist soil plant growth in these areas. 


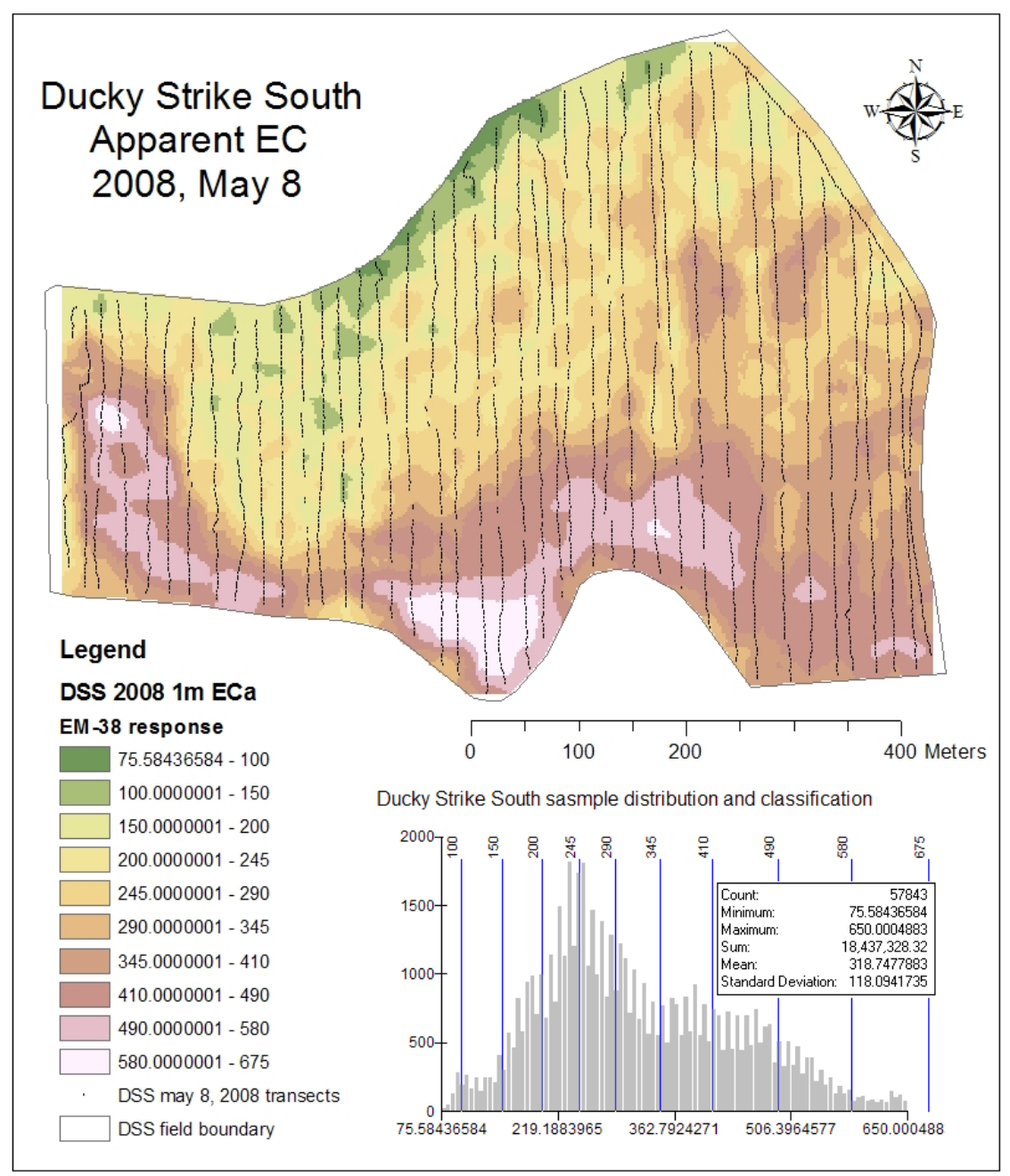

Figure 8. Map of EM-38 response developed from a soil salinity survey of a wetland pond. These readings are converted into soil salinity estimates based on a regression model developed between instrument readings and saturated extract soil salinity from field samples. The sample locations are chosen using software which ensures that the sample values fall across a normal distribution. 


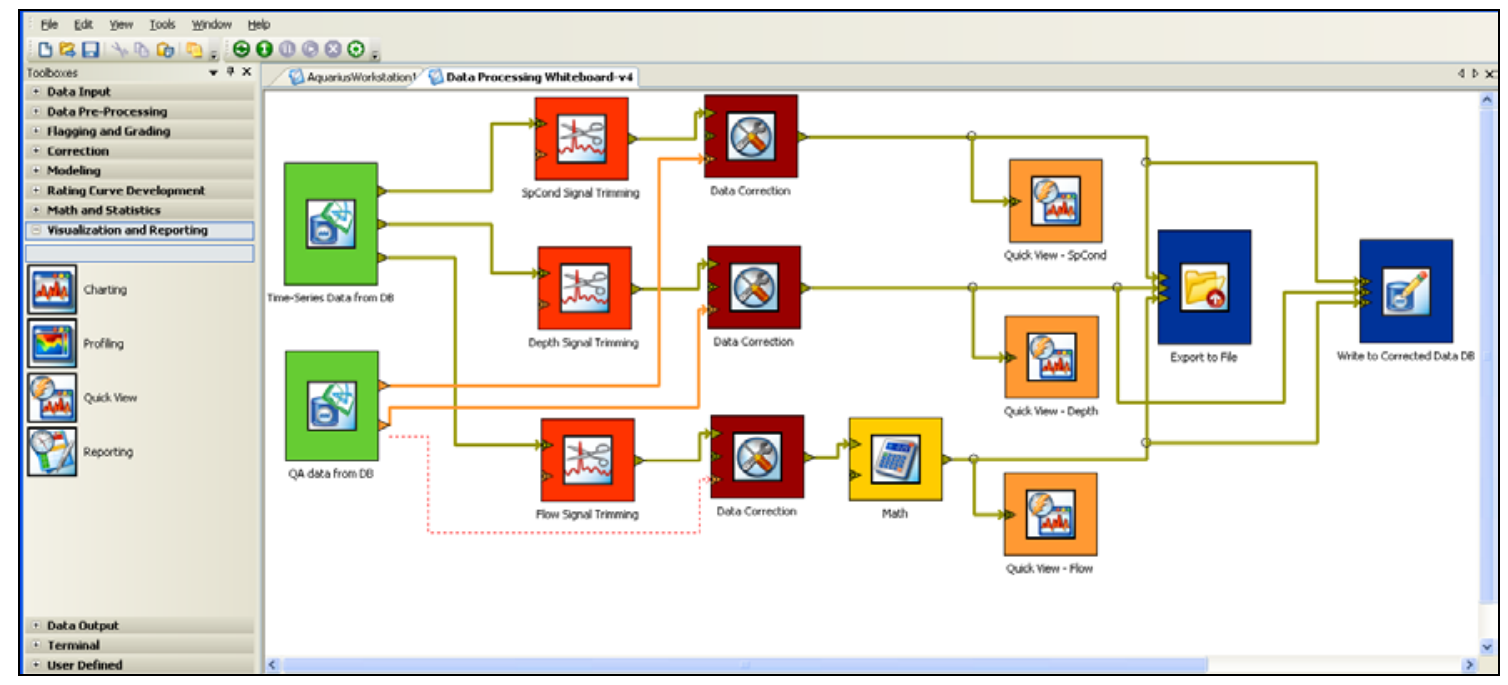

Figure 9. Data processing whiteboard within the Aquatic Informatics Aquarius software. Continuous environmental monitoring data is merged with weekly quality assurance data collected at each monitoring station to allow continuous error checking and data corrections to take place. RTSM requires continuous data processing to allow daily salinity assimilative capacity forecasts to be made. 


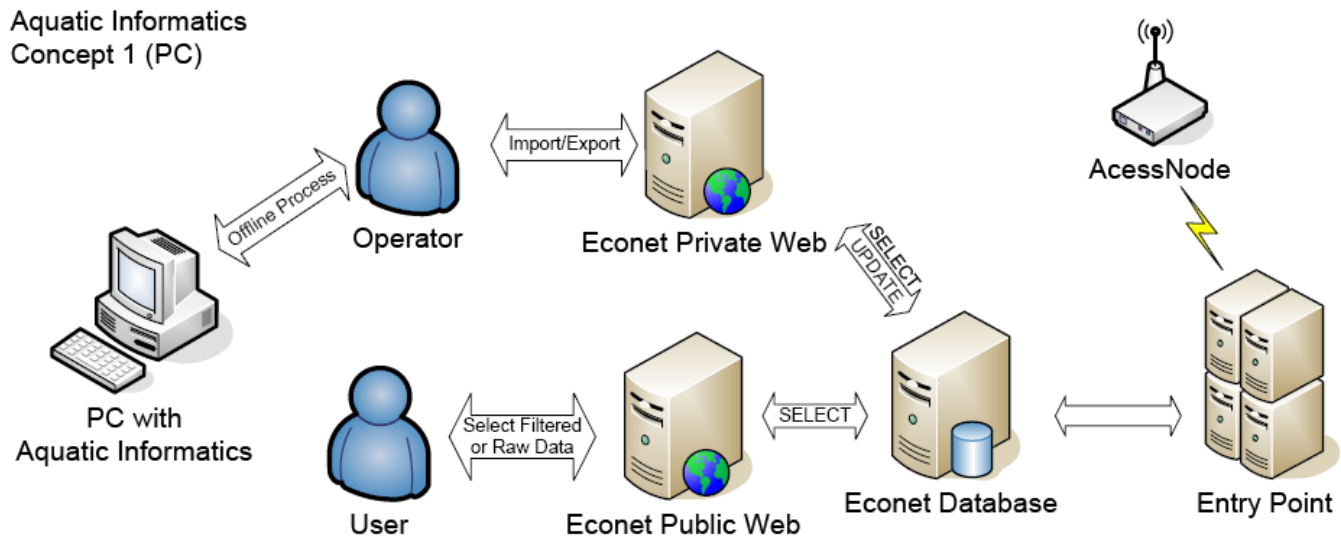

Figure 10. Protocol for replacing preliminary data on the NIVIS public website with data after quality assurance filtering has been completed. 